\title{
Limiting the Hurtful Oxidative Stress and Seasonal Physiological Adaptations in Seashore Paspalum through the Use of Banana Waste Biochar and Compost Mixtures
}

\author{
Dounia Fetjah ${ }^{1 *}$, Bouchaib Ihssane ${ }^{2}$, Zaina Idardare ${ }^{3}$, \\ Lalla Fatima Ezzahra Ainlhout ${ }^{4}$, Laila Bouqbis ${ }^{4 *}$ \\ ${ }^{1}$ Laboratory of Biotechnology, Materials and Environment, Faculty of Sciences, Ibn Zohr University, Agadir, \\ Morocco \\ 2 Laboratory of Applied Organic Chemistry, Faculty of Sciences and Techniques, Sidi Mohamed Ben Abdellah \\ University, Fez, Morocco \\ ${ }^{3}$ Higher Institute of Maritime Fisheries, Agadir, Morocco \\ ${ }^{4}$ Laboratory of Biotechnology, Materials and Environment, Faculty of Applied Sciences, Ibn Zohr University, \\ Ait Melloul, Morocco \\ *Corresponding author's e-mail: fetjahdounia194@gmail.com, Laila.bouqbis@gmail.com
}

\begin{abstract}
The study's purpose was to reduce the oxidative stress, seasonal physiological changes of paspalum vaginatum and ameliorate soil properties through the addition of banana waste biochar and compost. Different rates of organic amendments were incorporated into sandy loam soil to investigate their impact on paspalum physiological, biochemical, and development in pot and field settings over three seasons (winter, spring and summer). Under the conditions of these two places, paspalum leaves gas exchange characteristics, stomatal traits, anatomy traits, relative water content, proline, antioxidant enzyme activities, and paspalum pigments were determined. For the irrigation system, two rates were chosen: $20 \%$ and $60 \%$ of the water holding capacity of the control plot WHC. In this study, two advanced statistical analyses were conducted. A factor analysis of mixed data (FAMD) was performed for the analysis of the effect of our charcoal on soil data. Meanwhile, the impact of banana waste biochar on biological activities was investigated using multiple factorial analysis (MFA). The use of biochar and compost blends boosted the cation exchange capacity (CEC) of treated soils, according to our findings. Furthermore, the use of banana waste biochar improved biological basis in the summer season compared with previous seasons. Different antioxidant capacities in seashore paspalum were boosted in the improved soils compared to the untreated ones.
\end{abstract}

Keywords: banana waste biochar, oxidative stress, MFA, FAMD.

\section{INTRODUCTION}

Drought has a tremendous impact on crop production and soil quality (Kammann et al. 2011). In dry and semi-arid zones, plants are able to resist the tough environment due to many adaptations, including limiting stomata conductance, reducing leaf water potential, adapting photosynthetic rate, and closing stomata. Despite the fact that the drought increased reactive oxygen species (ROS), vegetation secreted antioxidant enzymes to safeguard themselves from the effects of ROS (Ghassemi-Golezani and Farhangi-Abriz, 2019). In terms of environmental stressors, Paspalum Vaginatum Swartz is considered a native plant (Ibitayo et al.1981). It has a high resistance to abiotic factors and is commonly used in tennis courts, public parks, and golf courses. Nonetheless, the quality of golf courses in the south of Morocco has increased in recent years. However, its soils are currently depleted in organic matter. All of these factors make tennis court and golf courses management in such arid regions an important ecological 
issue, particularly when the requirements for watering paspalum are considered.

All of these challenges prompted the authors to consider a novel approach to addressing water crisis and deteriorated soil conditions in this region. Numerous approaches have been suggested in this context, including raising carbon stocks content via biochar as a tool for managing degraded soils.

Biochar can significantly modify the ROS of grasses by scavenging antioxidant enzymes. It can also provide an efficient nutrients uptake into the root zones of the grasses. Furthermore, earlier research revealed that using charcoal as a golf course supplement could strengthen the physicochemical, biological, and physical qualities of treated soils (Brockhoff et al. 2010; Cornelissen et al. 2013; Carey et al.2015; Vaughn et al. 2018).

Two studies were conducted in pots and in the field to assess the combined effect of organic amendment on a sandy loam soil and on Paspalum vaginatum watered with two water treatments (60 percent and 20 percent of the water holding capacity of the control). The novelty in this survey was the comparison between the physiological measurement and biochemical analyses under pot and field conditions using several qualitative and quantitative methods. A multiple factorial analysis (MFA) was conducted to explore the role of banana waste biochar incorporation on seashore paspalum growth using statistics from the biochemical and physiological data obtained over three episodes (winter, spring and summer). In turn, a factor analysis of mixed data (FAMD) was used to assess the $\mathrm{pH}$ and electrical conductivity of sandy loam soil. The purpose of this study was to select the optimum combination soil amendment on development and various physiological and biochemical parameters of paspalum vaginatum under water supply regimes and to make comparisons about their repercussions under pot and field conditions.

\section{MATERIALS AND METHODS}

\section{Experimental design}

The soil for the study was gathered in the south of Morocco, specifically in Taroudant, at a depth of $0-20 \mathrm{~cm}$. The soil sample was sieved to achieve $2 \mathrm{~mm}$ particles after air drying and grinding. The soil contains $33.39 \%$ of coarse silt, $2.05 \%$ of fine silt, $1.20 \%$ of clay, $39.96 \%$ of coarse sand, $23.40 \%$ of fine sand. For the elemental composition: $0.007 \%$ of total nitrogen $\mathrm{Nt}, 0.201 \%$ of $\mathrm{P}_{2} \mathrm{O}_{5}$, $2.5 \%$ of total organic matter MOt, $1.45 \%$ of total organic carbon COt, $0.357 \%$ of $\mathrm{K}_{2} \mathrm{O}, 0.192 \%$ of $\mathrm{Na}_{2} \mathrm{O}, 0.933 \%$ of $\mathrm{CaO}$, and $0.391 \%$ of $\mathrm{MgO}$. The contents of iron, manganese copper and zinc were, $0.4,7.4,0.9$, and $2.6 \mathrm{ppm}$, respectively. The waste feedstock of banana leaves was pyrolyzed in a Moroccan pyrolysis process heater based on a model by Prof. Claudia Kammann (Bouqbis et al. 2016). The detailed physicochemical properties of banana waste biochar have previously been reported (Fetjah et al. 2021a). In turn, compost was purchased from Agadir.

Firstly and at the end of planting, $\mathrm{pH}$ and electrical conductivity (EC) were quantified using the method of (Blakemore et al. 1981). Three statuses of soils: soil before planting, soil of field and soil of plastic pot experiment were analyzed to determine the cation exchange capacity (CEC) following the method of (Metson, 1956).

Seeds of Paspalum vaginatum Swartz were planted in damp peat-filled plastic trays $(33.5 \times 50 \mathrm{~cm})$. After four weeks, the seedlings were transplanted into plastic tubes $(13 \mathrm{~cm}$ tall, $12.5 \mathrm{~cm}$ wide; four plants per tube) filled with either basic soil or soil treated with banana waste biochar or compost. Ten mixtures were prepared with soil and organic amendments (compost and banana waste biochar) with four replications from each treatment: (1) CTR (control with $100 \%$ of dry soil (2) 3C0B had included $97 \%$ soils and just $3 \%$ of compost, while (3) 3B0C comprised $97 \%$ dry soil, $3 \%$ of biochar, and zero percent compost, (4) 3B3C made by $3 \%$ biochar $+3 \%$ compost and $94 \%$ of dry soil, (5) 3B6C containing $3 \%$ of biochar, $6 \%$ compost and $91 \%$ of dry soil, (6) 6B0C mixture of $6 \%$ of biochar $+0 \%$ compost and $94 \%$ of dry soil, (7) $6 \mathrm{~B} 6 \mathrm{C}$ mixture of $6 \%$ of biochar $+6 \%$ compost and $88 \%$ of dry soil, (8) $6 \mathrm{C} 0 \mathrm{~B}$ mixture of $0 \%$ of biochar + $6 \%$ compost and $94 \%$ of soil, (9) $6 \mathrm{~B} 3 \mathrm{C}$ containing $6 \%$ of biochar, $3 \%$ compost and $81 \%$ of dry soil, and (10) test contained soil and NPK. The test treatment was a supplementary treatment in this study, in order to compare its effect with banana waste and compost treatments. In addition, paspalum vaginatum received two irrigations, $20 \%$ and $60 \%$ of WHC of sandy loam soil. For example, the plant cultivated in treatment $6 \mathrm{~B} 6 \mathrm{C}$ received $(676 \mathrm{ml})$ for $60 \%$ of $\mathrm{WHC}$ and $204 \mathrm{ml}$ for $20 \%$ of $\mathrm{WHC}$, the same irrigations 
were carried out under field and pot conditions, plants received different irrigation depending on mixture of soil and organic amendments. In this study, different rates of Banana waste Biochar were applied, i.e. $6 \%$ B0C correspond to $137.04 \mathrm{Mg} \cdot \mathrm{ha}^{-1}, 3 \%$ B0C in $68.52 \mathrm{Mg} \cdot \mathrm{ha}^{-1}$.

The same mixtures were prepared for field with four repetitions for each treatment, the area of field was $22100 \mathrm{~cm}^{2}$ while the depth of soil and organic amendment was $25 \mathrm{~cm}$.

At the beginning of each experiment, paspalum vaginatum was irrigated daily for eight weeks in the two experiments pot and field. The stress application duration was ten months with a minimum of irrigation water $20 \%$. The temperature and humidity for the paspalum vaginatum was measured during the year for both field and pot experiment with a UNI-T UT330A data logger.

\section{Gas exchange, chlorophyll pigment content and proline}

Over three seasons, leaves paspalum gas exchange variables were assessed through the use of Infra-Red Gas Analyzer (IRGA) (LCi-portable photosynthesis System, ADC, Hertfordshire, UK) (Fetjah et al. 2021b). In order to extract pigment, the method reported by (Lichtenthaler, 1987) was followed in three juvenile paspalum leaves using a UV-1600PC spectrophotometer. For proline quantification, the method described by (Bates, 1973) was used. Proline concentration was expressed in $\mu \mathrm{mol} \cdot \mathrm{g}^{-1} \cdot \mathrm{FW}$. Three repetitions were done for each experiment.

\section{Relative water content (RWC)}

$0.5 \mathrm{~g}$ of fresh weight (FW) of paspalum vaginatum leaf was evaluated during the study. It was then immersed in tap water. We measured its turgid weight after a day (TW). Afterward, the dry weight (DW) of paspalum leaf sample was determined in oven-dried at $80{ }^{\circ} \mathrm{C}$ for 48 hours. The measurements were taken twice: once at 6 a.m. and once at 12 a.m. (Nikpour-Rashidabad et al., 2019, Sairam et al., 2002). RWC was calculated using the equation.

$$
\begin{gathered}
R W C(\%)=(F W-D W) / \\
(T W-D W) \times 100
\end{gathered}
$$

\section{Leaf stomatal traits}

The abaxial surface of the leaflets was used to obtain stomata imprints. After cleaning the surface of the leaf of Paspalum vaginatum with a soft brush, a thin layer of nail polish was applied and allowed to dry for 10-15 minutes. Afterwards, the transparent tape was applied to the area and carefully removed. Stomatal number, density, and size parameters such as (LS: stomata length, WS: stomata width, Lo: length of the ostiole, Wo: width of the ostiole) were calculated by (BX51, light microscopy Olympus, Tokyo, Japan).

\section{Anatomical leaf characters}

The leaves of Paspalum vaginatum were thinly cut into a slide during the three seasons of winter, spring, and summer 2019/2020. Then, a drop of water was placed on the slides to aid in the examination of the examined sections (BX51, Olympus light microscopy, Tokyo, Japan). For each leaf treatment, five replicates were generated.

\section{Determination of plant enzyme activity}

Aebi et al. (1984) calculated catalase (CAT) activity after ingesting $\mathrm{H}_{2} \mathrm{O}_{2}$ for 1 minute at 15 sec intervals at $240 \mathrm{~nm}$. The test mixture involved paspalum leaf extract at concentrations of $100 \mathrm{mM}$ and $30 \mathrm{mM}$ buffered potassium phosphate and $\mathrm{H}_{2} \mathrm{O}_{2}$, respectively. The SOD activity was measured using nitroblue tetrazolium (NBT) with a mixture of $50 \mathrm{mM}$ sodium phosphate buffer, $0.12 \mathrm{mM}$ riboflavin, $1.72 \mathrm{mM}$ Nitro blue solution, $1 \%$ Triton X-100, and $201 \mathrm{mM}$ methionine, according to Beauchamp and Fridovich (1971). The POD activity was assayed at $470 \mathrm{~nm}$ in $\mathrm{H}_{2} \mathrm{O}_{2}$ incubated for 3 minutes according to Chance and Maehly's explanation (1955). The activity of APX was estimated making use of the extinction coefficient of ascorbate at $290 \mathrm{~nm}$ in $\mathrm{H}_{2} \mathrm{O}_{2}$ solution at intervals of $2.8 \mathrm{mM}^{-1} \mathrm{~cm}^{-1}$ at $290 \mathrm{~nm}$ in $\mathrm{H}_{2} \mathrm{O}_{2}$ solution at interval of $15 \mathrm{sec}$ up to $60 \mathrm{sec}-$ onds (Nakano and Asada (1981).

\section{Chemometrics analysis}

Two chemometric methods were used in this research: factor analysis of mixed data (FAMD) and multiple factorial analysis (MFA). FAMD employs a principal components technique to evaluate a data set that contains alike quantity 
and quality variables (Pagès et al. 2004). FAMD was used to contrast the physicochemical parameters of sandy loam soil in a wide range of experiments.

Because the dataset contains both quantitative parameters organized into groups and qualitative variables, MFA was the ideal statistical technique for this research study. MFA was used to evaluate the effect of edible amendment addition on seasonal physiological changes and biochemical analysis of seashore paspalum grown in two different water sources. Besides, a two-way ANOVA was used to assess whether banana waste biochar had a greater effect on the cation exchange capacity CEC of the paspalum vaginatum plant in the three soil statuses. RStudio was used to perform all statistical computations Version 1.4.1717, with the FactoMineR and Factoextra packages (Husson et al. 2007).

\section{RESULTS AND DISCUSSION}

\section{Effect of banana waste biochar on soil properties}

In terms of various group contributions, type of treatment seems to have a major contribution to the both axes 1 and 2. This indicates that the two modes (experiment and type treatment) had an extremely massive impact on all samples, especially the distribution of the physicochemical values analyzed.

The group "EC" contributes greatly to MFA axis 1 but not to axis 2. Same is true for the contribution of $\mathrm{pH}$ and period groups to axis 1 . The experiment had a serious influence on axis 2. (Fig. 1A).

In Figure $1 \mathrm{~B}$, the loading plot and vector showed the effect of banana waste on $\mathrm{pH}$ and EC of soil.-The first factorial axis clarifies variance related to $\mathrm{EC}, \mathrm{pH}$, and period with $(16.2 \%$ of the total variance), whereas the second axis (9.3 percent inertia) signifies experiment condition such as field or plastic pot and type of treatment (type trt). Overall, the modified treatments in a plastic pot produce high levels of $\mathrm{EC}$, in particular 6B3C_20PF, 6B3C_20PF, and 6B6C_PF. In general, the treatments mostly on left are basic because they had high $\mathrm{pH}$ values. In contrast, the treatments 3B3C_20FE, 3B3C_60FE, 3B3C_20FF, 3B3C_60FF had low values of $\mathrm{pH}$ and EC. Furthermore, the
$\mathrm{pH}$ and EC of the CTR_60PE treatment were measured at the first months of planting, resulting in low values of physico-chemical values (Fig. 2). On the other hand, the treatments called test contained soil with NPK 10-30-10 as a type treatment, are all at the upper edge of MFA axis 2 and seem to have high EC values when compared to others (Fig. 2).

The soil of paspalum showed a substantial outcome on cation exchange capacity with different rates of biochar, compost as a single addition or combined effect of the two amendments under two experiment conditions field and pot. Indeed, Table 1 shows that all the $\mathrm{p}$ values $<0.0001$, indicating extremely significant effects on the CEC. As a matter of fact, the use of banana biochar has a beneficial impact on the treatments.

The purpose of the CEC measurement was to assess the efficacy of banana waste biochar on properties of soil in a pot or in the field on seven treatments:control 60\%, 6C0B $20 \%$, $6 \mathrm{C} 0 \mathrm{~B} 60 \%, 6 \mathrm{~B} 0 \mathrm{C} 20 \%, 6 \mathrm{~B} 0 \mathrm{C} 20 \%, 6 \mathrm{~B} 6 \mathrm{C} 20 \%$ and $6 \mathrm{~B} 6 \mathrm{C} 60 \%$. Table 2 contains the findings of the two-way ANOVA results followed by a Scheffe test to compare the means in pairs. The impact of banana waste biochar on a sandy loam soil was explored in this research. The electrical conductivity was higher on soil at the beginning of the experiment in pot treatments and lower for the field treatments (Fig. 1B, and Fig. 2). At the end of the treatment period, the amended soils treatment seemed to have low EC values in both the field and the pot treatments.

For $\mathrm{pH}$, amended treatments in pot are basic, hence the treatments in field tend to have neutral $\mathrm{pH}$ behavior. Generally, the studied banana waste biochar is alkaline (Fetjah et al. 2021), which tended to neutralize the amended treatments in field and pot. In line with the obtained results, Castaldi et al. 2011, revealed that adding alkaline biochar amendment with ( 3 and $6 \mathrm{~kg} \mathrm{~m}^{-2}$ ) in a wheat sown field soil enabled to neutralize $\mathrm{pH}$ from 5.2 to 6.7 over two growing seasons. In fact, CEC was higher in the amended soils in field compared to the amended soils in a plastic pot. Moreover, the addition of banana waste biochar enhanced the CEC of soil. In the considered case, CEC was higher with the treatment $6 \mathrm{~B} 6 \mathrm{C}$ at $60 \%$ of WHC. Due to the formation of carboxyl components on the surface of banana waste biochar, the treated soils showed an increase in CEC values compared to the untreated soils (Glaser et al. 2003). 
a)

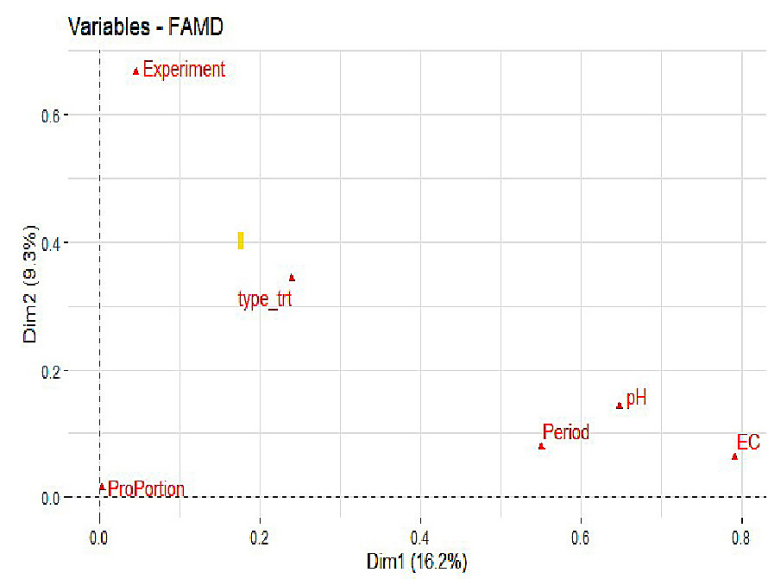

b)

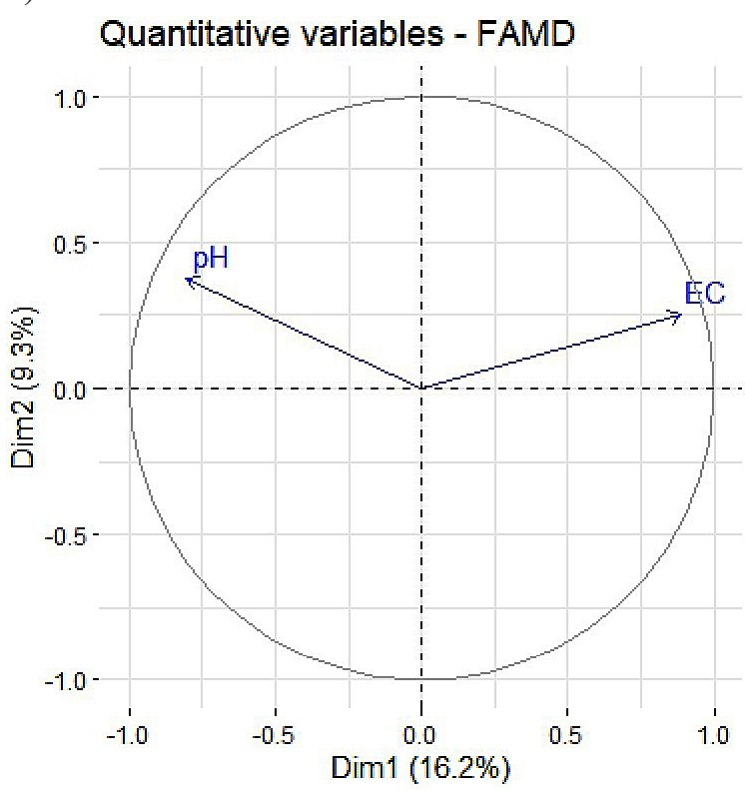

Fig. 1. (a) Assessment of physico-chemical data from the Paspalum Vaginatum Swartz with factor analysis of mixed data (FAMD), (b) Loading plot of Paspalum vaginatum $\mathrm{pH}$ and electrical conductivity over three seasons

\section{The influence of biochar made from banana waste on physiological performance}

During three different seasons (winter, spring, and summer), the implications of specific percentages of banana waste biochar on physiological characteristics of paspalum vaginatum were assessed in two locations: field and a plastic pot. (Fig. 3A). Different parameters were investigated, including relative water content, stomatal leaf traits, photosynthesis, fresh weight of aerial paspalum biomass (FWBA), chlorophyll parenchyma thickness (CPT), and total parenchyma thickness (TPT). MFA was used to unveil the overall impact of banana waste biochar, experiment season (winter, spring, and summer), and conditions (well-watered $60 \%$ of WHC and limited water $20 \%$ of WHC) associated with physiological data collected during the two trials.

The five sets of variables' coordinates were shown and utilized to construct a model of the groups (Fig. 3A). The dimensions were determined using the first two components of MFA (Dim 1 and 2 in the figure), which accounted for 21.2 and $15.6 \%$ of the dataset total variance, respectively. Following the addition of biochar and compost, the contribution of individual groupings of variables was calculated. Different implications

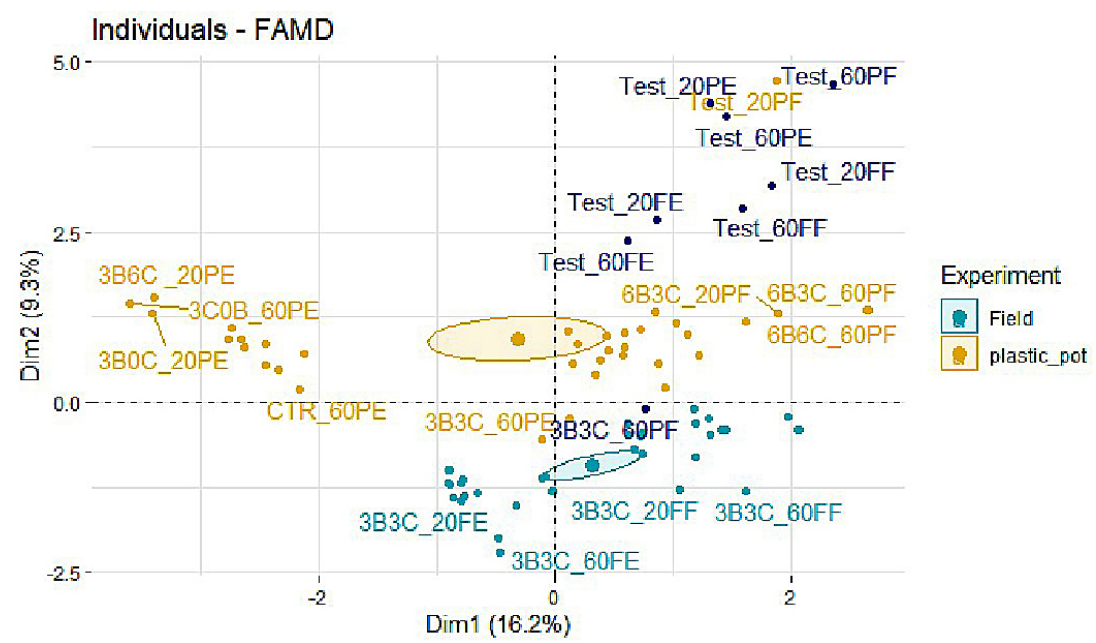

Fig. 2. Score plot showing the effect of the banana biochar on $\mathrm{pH}$, electrical conductivity of soil at the first of planting, and at the end of experiment in the two experiments (field and plastic pot) 
Table 1. Findings of two-way ANOVAs on cation exchange capacity with influences of banana waste biochar-compost addition and water supply regimes (60 and 20\%)

\begin{tabular}{|l|c|c|}
\hline \multicolumn{1}{|c|}{ Description } & Fisher value & P-value \\
\hline Type of treatment & 10.961 & $<0.0001$ \\
\hline Condition & 68.201 & $<0.0001$ \\
\hline Type of treatment $\times$ Condition & 5.807 & $<0.0001$ \\
\hline
\end{tabular}

can be reached for the performance of various sets of variables after biochar and compost incorporation in terms of how it contributes for every varying group to axis 1 . Certainly, the involvement of leaf anatomy physiological parameters in Figure 3A (chlorophyll parenchyma thickness and total parenchyma thickness) appears to be the most significant $(\mathrm{RV}=49.71 \%)$, followed with the contribution of weight biomass of $(\mathrm{RV}=$ $49.17 \%$ ). For the axis 2 of MFA, the most significant contribution was from photosynthesis with ( $\mathrm{RV}=59.74 \%$ ), then the contribution of stomatal leaf traits appears important with $(\mathrm{RV}=49.95 \%)$, the lowest contribution of relative water content for axis 2 was $47.06 \%$.

Figure 3B and Figure 4 showed the physiological responses of paspalum vaginatum corresponding to the three seasons. The correlation coefficients between these variables are shown in Figure $3 \mathrm{~B}$ by loading plot. According to axis 1 , during the summer season, paspalum cultivated in the amended treatments under field had clearly higher values of fresh weight of aerial biomass FWBA, chlorophyll parenchyma thickness CPT, total parenchyma thickness TWT and relative

a)

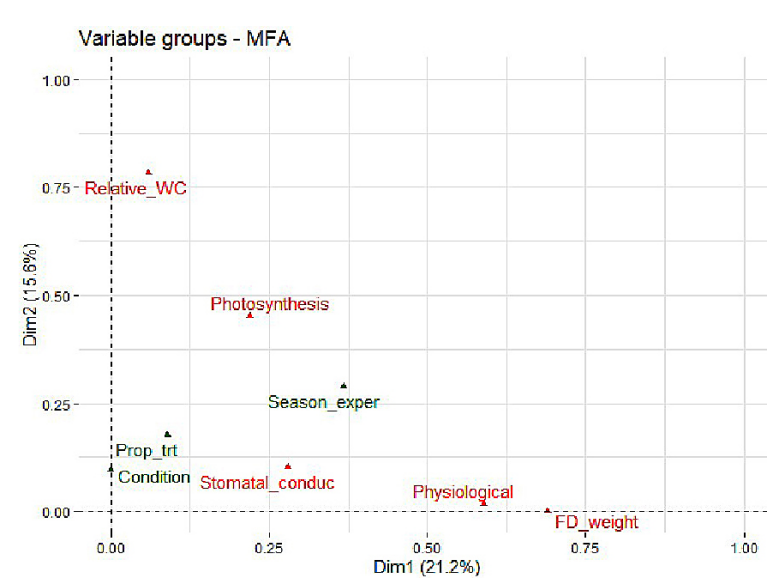

Table 2. The Scheffe findings investigate treatment options for soil cation exchange capacity in sandy loam soil under two water resource conditions (60 percent and 20 percent)

\begin{tabular}{|c|c|c|}
\hline Treatments & $\begin{array}{c}\text { CEC } \\
\text { (meq/100g of soil) }\end{array}$ & Groups \\
\hline Control60\% & 3.00 & $\mathrm{~B}$ \\
\hline $6 \mathrm{C} 0 \mathrm{~B} 20 \%$ & 4.70 & $\mathrm{~B}$ \\
\hline $6 \mathrm{C} 0 \mathrm{~B} 60 \%$ & 13.47 & $\mathrm{AB}$ \\
\hline $6 \mathrm{~B} 0 \mathrm{C} 20 \%$ & 15.17 & $\mathrm{AB}$ \\
\hline $6 \mathrm{~B} 0 \mathrm{C} 60 \%$ & 17.82 & $\mathrm{~A}$ \\
\hline $6 \mathrm{~B} 6 \mathrm{C} 20 \%$ & 21.26 & $\mathrm{~A}$ \\
\hline $6 \mathrm{~B} 6 \mathrm{C} 60 \%$ & 22.89 & $\mathrm{~A}$ \\
\hline
\end{tabular}

water content at midday and predawn (Individual score plot; Figure 2B). The same positive effect was revealed for paspalum vaginatum which grew in the amended treatments (6B6C_20SS, 3B0C_60SS, 6C0B_60SS, 3B6C_60SS, 3B6C_20SS and 3B3C_60SS) under the pot plastic condition. They had low values of leaf stomatal traits. On the other hand, MFA revealed that the seashore paspalum cultivated in the amended treatments in both winter and spring seasons had a low physiological response and high values of stomatal traits. Similarly for axis 2, the gaseous exchange behavior of the paspalum leaf appeared to be absolutely vital with amended treatments under field during the summer season, in comparison with control in the winter and spring seasons (Fig. 3B). Both axes showed that control treatment (CTR) at pot plastic during the winter and spring seasons had low values of physiological traits and relative water content but medium

b)

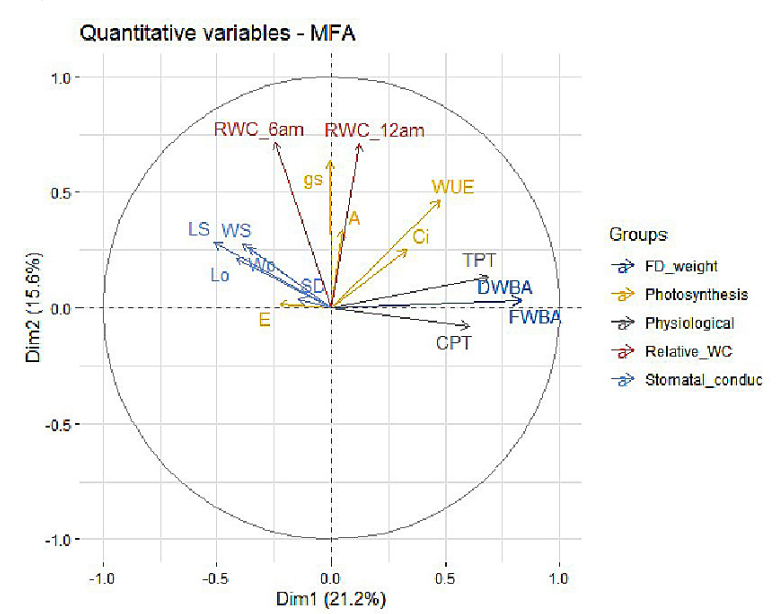

Fig. 3. Multivariate statistical analysis (MFA) of physiological parameters in paspalum vaginatum over three seasons: (a) Depiction of 5 groups of paspalum vaginatum factors under two water conditions, (b) Variable loading plot of the two first principal components 
values of stomatal traits. The temperature and humidity of paspalum vaginatum was recorded during one year. On average, the temperature of paspalum was $21.4{ }^{\circ} \mathrm{C}$ and mean humidity was $69.5 \%$.

In the winter and spring seasons, low photosynthesis, stomatal conductance rates and RWC were showed in the seashore paspalum cultivated on the soil amended with banana waste biochar application in a pot and field.Tanure et al. (2019) demonstrated that the implementation of biochar , during harsh conditions, the photosynthetic activities, stomatal conductance, and leaves RWC. Furthermore, Abideen et al. (2020) discovered that adding $2.5 \%$ biochar lowered RWC, as a result of the reduction of relative water content in plants. In addition, Paneque et al. (2016) found a decrease in stomatal conductance in sunflower seedlings under water deficit after treating soil with biochar. The study of Hafez et al. (2020) found that RWC gotten better more prominently with the vermicompost-biochar mixture application than biochar as a particular application, which is consistent with the obtained results. Nonetheless, Abideen et al. (2020) realized that using biochar improved growth and photosynthesis during a water stress.

However, in the summer season, significant physiological response was observed for paspalum vaginatum. In the present study, the banana waste biochar addition increased growth, photosynthesis, RWC, in the amended treatments in a field compared to the pot treatments (Figs. 2B, $2 \mathrm{C})$. In turn, the growth of paspalum vaginatum in the colder months was lower than in the summer period, this is conformity with the results of Liu et al. (2016), who assumed that the bamboo biochar increased the rice crop yield over two crop seasons. Hence, the stomatal aperture was higher in the leaves of the paspalum grown in a pot, compared to a field.

Under water stress, stomatal density (SD) increased in a leaf of the paspalum cultivated in compost and banana waste biochar combination addition in a pot, while SD decreased with the amended treatments under field during the summer season (Fig. 3B). For the winter and spring season, SD noticed a low decrease on the amended treatments, compared to untreated treatments and control under the two conditions (pot and field). In numerous studies, drought was the main reason to increase leaf stomatal density in Solanum melongena ( $\mathrm{Fu}$ et al. 2013). Furthermore, (Xu and Zhou 2008) realized that during modest rainfall, the stomatal density enhanced while water declined as a whole, whereas during the dry seasons, SD dropped significantly, suggesting that grass seems to have the power to adapt to the changes in the environment via leaf flexibility.

The increased growth of paspalum during the summer period might be attributed to the large nutrients produced by enhanced biochar decomposition. In fact, the banana waste biochar took a time to decompose and enhanced

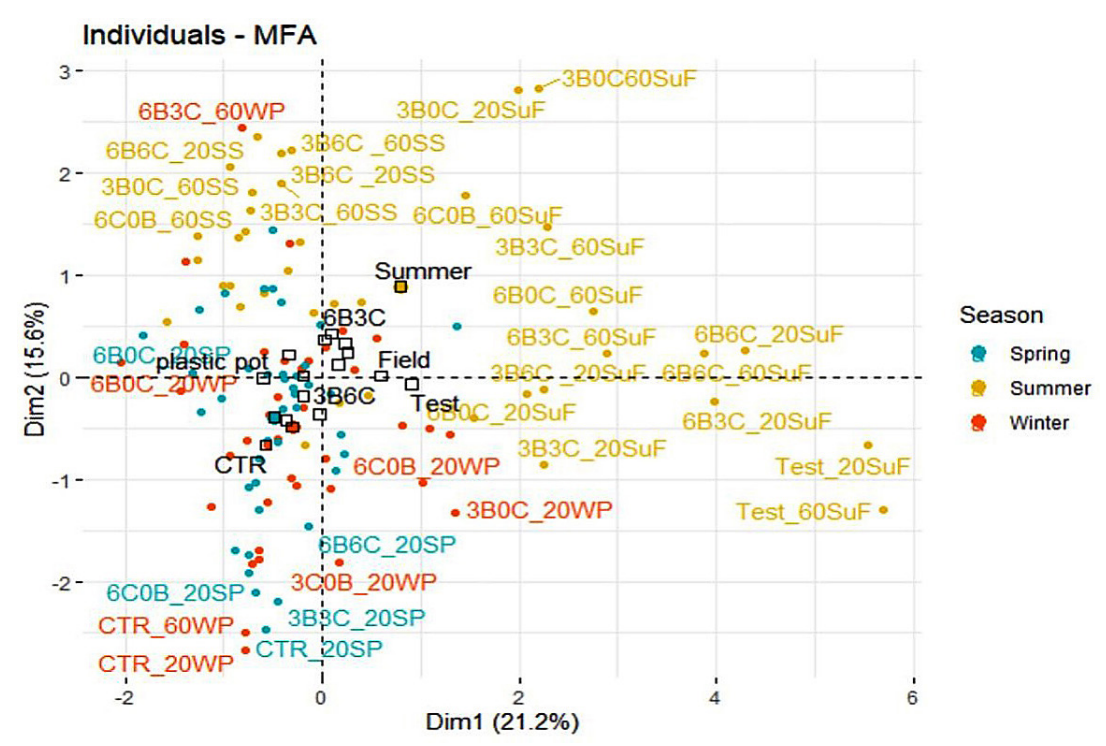

Fig. 4. A score plot illustrates the impact of banana waste biochar on treatment options of the two first principal components in two trials (field and plastic pot).

Key: WP winter in pot, SS summer pot, SP spring in pot, uF summer field 
all recorded studied characteristics, notably during the summer season (Glaser et al. 2002; Lehmann et al. 2003). Additionally, the test treatment which contained NPK and soil was supplementary data to compare the best combination biochar and compost on growth regulation of paspalum. Indeed, the four mixtures $6 \mathrm{~B} 6 \mathrm{C}, 6 \mathrm{~B} 3 \mathrm{C}, 3 \mathrm{~B} 3 \mathrm{C}, 6 \mathrm{~B} 0 \mathrm{C}$ at the two regimes were the best mixtures of amendment applied; these remedies resulted in higher fresh weight biomass and photosynthesis values. The biochar response was reported throughout the summer season, confirming the progressive degradation of biochar (Cross and Sohi, 2011). The obtained findings, as shown in Figure 3A and Figure $3 \mathrm{~B}$, revealed sections of each treatment that demonstrated the anatomical value adjustments of the seashore paspalum leaves exacerbated by drought stress. The thickness of chlorophyll parenchyma, and total parenchyma thickness significantly increased with amended treatments during summer under water stress.

In the winter and spring seasons, the stressed plants in pot showed the greatest reduction in all studied characteristics, especially control that received $20 \%$ of WHC when compared to stressexposed plants. Despite this, the amended plants had huge rise in chlorophyll parenchyma thickness under both irrigation levels. The plants that were treated with biochar made from banana waste and compost mixture produced the best results during the summer period, i.e. $6 \mathrm{~B} 6 \mathrm{C}$ and $6 \mathrm{~B} 3 \mathrm{C}$, compared with the control one.

a)

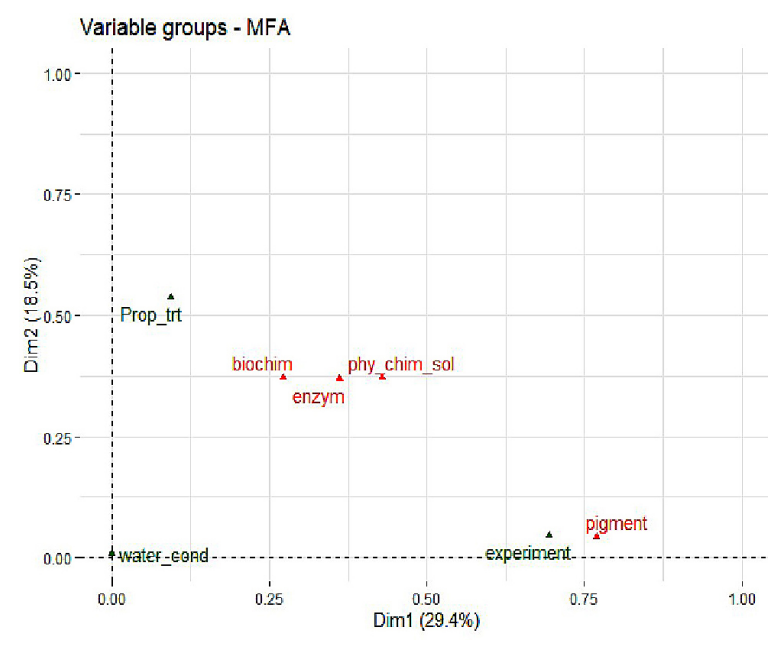

The results of the chemometric assessment, which used only ecophysiological attributes throughout the year, justify that the banana waste biochar and compost would increase the seashore paspalum species and boost its resistance to drought in semi-arid and arid regions.

\section{Banana waste's influence on chlorophyll pigment, proline, oxidative stress, and physicochemical assessment}

Under the application of $20 \%$ of WHC, changes in the four antioxidant activities: catalase, POD, SOD, and APX, were recorded in the final months of the paspalum growth to quantify the oxidative stress. Furthermore, the pigment and proline contents were evaluated also at the end months of the two experiments. Further, EC and $\mathrm{pH}$ of the soil were evaluated to analyze the influence of basic biochar addition on soil properties. Figure 5A showed that pigment group has a significant contribution to axis 1 and not to axis 2. This means that the pigment content had a large impact on the samples located at the axes 1, particularly based on the dispersal of the biochemical, physicochemical and physiological measurements at the last months of the two experiments. In this regard, the contribution of biochemical (proline analysis) groups was greater to MFA axis 2, followed by the "physico-chemical" group that had a moderate participation for some treatments coordinate axes 1 of a MFA and a high contribution to axis 2 of the MFA, and finally the

b)

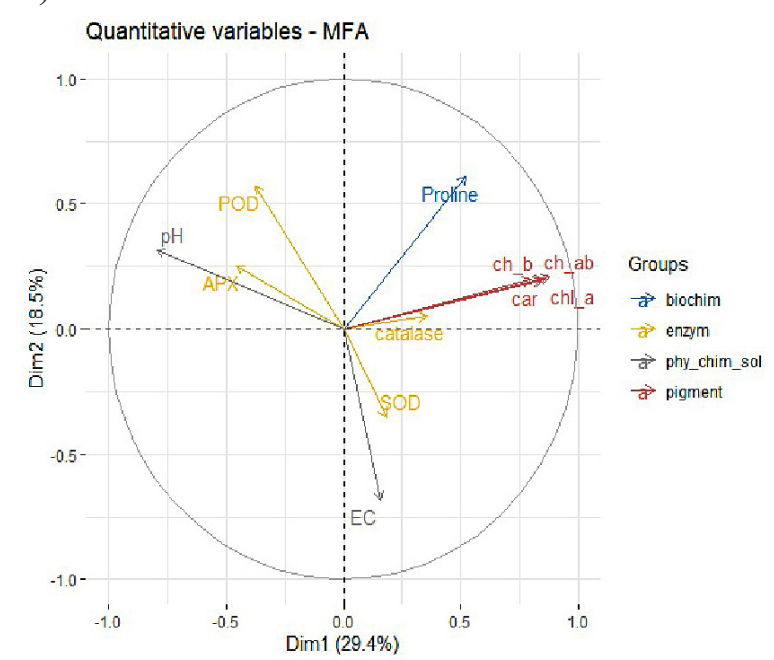

Fig. 5. Multivariate statistical assessment (MFA) of physiological parameters from Paspalum vaginatum over three seasons: (a) The two first principal components' variable loading plot,

(b) Characterization of four groups of paspalum vaginatum different factors under two water conditions 
enzymatic groups, which add value to the MFA axis 2. The three groups are prominent on the MFA axis 2 for distinguishing among the examined treatments (Fig. 5A).

With the weighted PCA method, loading plot revealed the correlation coefficients of the four variables (biochemical group: proline, enzyme activities group: POD, catalase, SOD, APX, pigment group: chla, chlb, total chlorophyll, carotenoids, physico-chemical groups: $\mathrm{EC}$ and $\mathrm{pH}$ ) and the MFA factorial axes. In this study, the loading plot in fig 5B was used to assess the impact of adding biochar made from banana biomass resources and compost mixtures on the physiological, physicochemical, and biochemical analyses, as well as paspalum vaginatum development replies under two water circumstances and two sequences constraints (pot and field).

Furthermore, the locations of the four factor groups were showcased on the "Depiction of groups" plot, wherein the coordinates had been estimated using the MFA's 1st two important components (Dim 1 and 2 on the diagram), which returned 47.9 percent of the overall variation of the different factors (Fig. 6A). The depiction of MFA treatments was shown in (Fig. 6C). Factorial axis 1 (29.4\% of the variance) completely delineated the treatments based on chlorophyll a, chlorophyll b, total chlorophyll, and carotenoids. In the field conditions, the paspalum grown in the amended treatments had higher chlorophyll levels. The second axis of MFA (which accounted for $18.5 \%$ of the variance) distinguished the treatments primarily based on antioxidant properties, pH, EC, and proline (Fig. 6). The obtained results confirmed that introducing banana waste biochar to amended treatments increased the chlorophyll levels compared to controls, which really is coherent with the findings obtained by Fetjah et al. (2021b).

Rehman et al. (2019) discovered that chlorophyll concentration played a significant role throughout rising biomass production, which explains why application of our biochar increased chlorophyll and biomass of paspalum. Over three seasons, a large decline in photosynthetic pigments in seashore paspalum cultivated in the amended treatments in a pot could be attributed to inadequate illumination seized by the leaves of the plant.

Under field conditions, the paspalum vaginatum grown in the control treatment accumulated a high concentration of proline. Previous studies explained that proline may contribute to minimize the impacts of water lost opportunity (Ain-Lhout et al. 2001; Zunzunegui et al. 2020).

Under severe drought, the proline content increased significantly in certain amended treatments (3B3C 20 and 6COB 20) and control (CTR 20 and CTR 60) under field conditions in the three

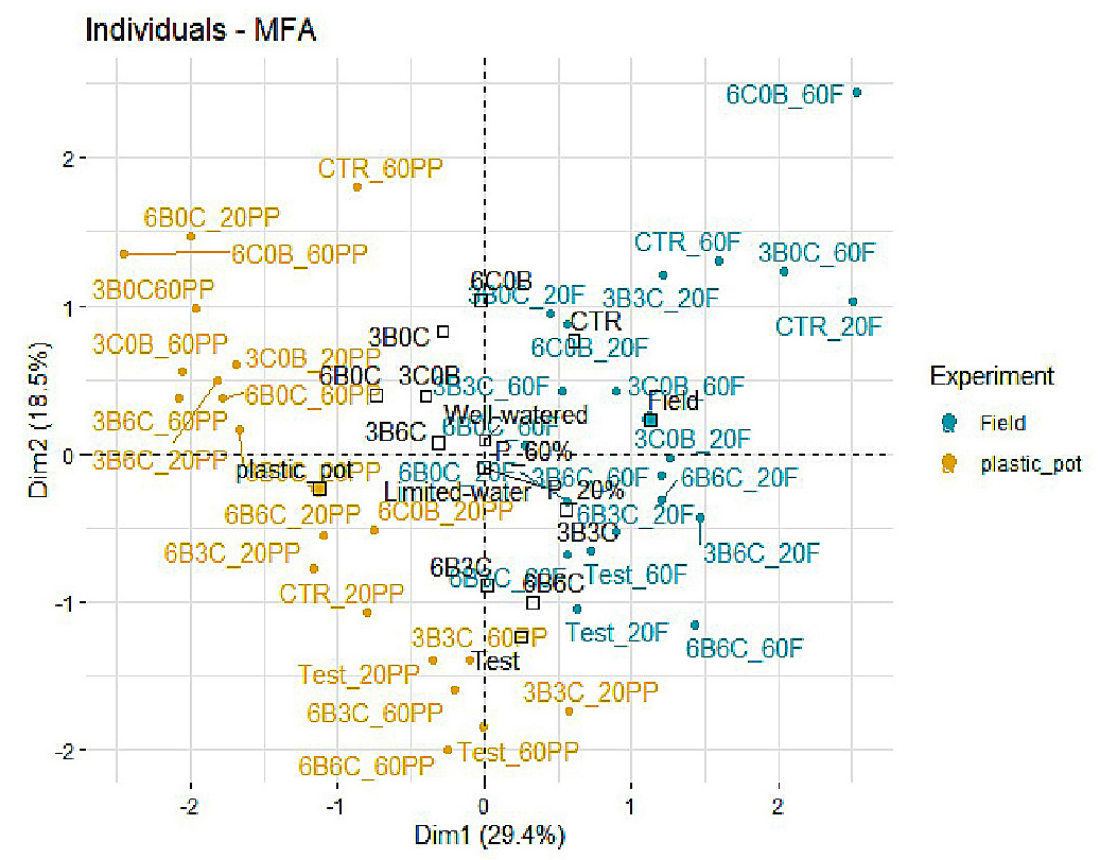

Fig. 6. In two trials, a score plot illustrates the impact of banana waste biochar on treatments available for the two first principal components (field and plastic pot). Field is symbolized by the letter F, and plastic pot is expressed by the letter pp 
seasons compared to control plants grown in pots (Fig. 6). The above increase could be a response to water scarcity. This result is agreement with the predictions of the research of Hussain et al. 2008, which found that water deficit impairs the performance of cellular membranes as well as induces cytoplasm water loss, both of which boost the proline content in paspalum vaginatum under drought conditions. Owing their desire to preserve the plasma membrane structure and redox regulation, the plants treated with biochar and chitosan may have lower proline content and the ability to withstand harsh conditions (Hafez et al. 2020).

Plants generally respond by producing reactive oxygen species under severe extreme drought (ROS). This brings down the plant's ability to use nutrients efficiently. Plants depend on enzymatic antioxidants to detoxify the hazardous levels of ROS (Wang et al. 2014; Baxter et al. 2014; Corpas et al. 2015; Ibrahim et al.2019).

The $3 \mathrm{~B} 3 \mathrm{C}$ as well as $6 \mathrm{~B} 6 \mathrm{C}$ treatments significantly reduced the oxidative stress compared to the samples on the left side under the pot conditions (Fig. 6). The individuals with the strongest antioxidant activities exhibited the most benefit from the treatment. Under pot conditions, seashore paspalum grew well with the amendments, which included the use of antioxidant enzymes APX and POD. This also demonstrated the beneficial impacts of biochar on the activity of certain antioxidant enzymes. In fact, Hafez et al.2020 found that the exposure to stress conditions resulted in the evolution of numerous antioxidant enzymes; this result matched with the obtained findings.

In this survey, paspalum vaginatum cultivated in banana waste biochar and compost mixtures treatments reduced oxidative stress. Indeed, charcoal and compost-treated soils support plants to possess greater antioxidant capacities; this outcome could be attributed to the fact that the two amendments can restrict the gene function associated with paspalum defense under adverse conditions (Jaiswal et al. 2020).

This present research proves the influence of banana waste biochar on attempting to reduce oxidative stress and enhancing the physiological characteristics of seashore paspalum under water shortages, particularly in the field when compared to a pot. Furthermore, banana waste biochar improved the soil quality by increasing cation exchange capacity. These findings are supported by MFA analysis, which emphasized the performance of the $\mathrm{pH}$, EC of soil, biochemical analyses, and antioxidant activities of paspalum vaginatum under stressful conditions. The treatments in the field were more similar in terms of measured traits, whereas the treatments in the pot were separated based on banana waste and compost addition and water holding capacity $(20 \%$ or $60 \%)$.

\section{CONCLUSIONS}

The current study discovered that compost and biochar mixtures improved the physiological, anatomical, and biochemical traits of paspalum vaginatum under pot and field conditions during the three seasons. Additionally, banana waste biochar maintained the stability of the leaf water status, even under $20 \%$ of WHC during summer seasons and enhanced relative water content for amended treatments compared to unamended treatments. In comparison to the amended treatments in plastic pots, the obtained findings demonstrate that the amended treatment methods in field trials had an amazing response of photosynthetic activity and evolved biomass weight under drought. Furthermore, banana waste biochar had an effective antioxidative system content evolution that helped to alleviate oxidative stress, even during the dry season.

\section{Acknowledgments}

We would like to thank all those who helped fund this work. Project 2016-2018: Use of stable isotopes to explore water relations in the Argan tree. This project is funded by University Ibn Zohr. Annual budget (2016-2021) of University Ibn Zohr allocated to the laboratory of Biotechnology, Materials and Environment, Faculty of Sciences, Ibn Zohr University, Agadir, Morocco. Budget and Equipment of the Research Center of the Faculty of Science Agadir, University Ibn Zohr. Budget and equipment of the Faculty of Applied Sciences, Ait Melloul, University Ibn Zohr. Equipment of the Polydisciplinary Faculty of Taroudant, University Ibn Zohr. As well as, Budget for scientific research allocated by the National Center for Scientific Research, CNRST, Rabat, Morocco.

\section{REFERENCES}

1. Abbas T., Rizwan M., Ali S., Zia-ur-Rehman M., Farooq Qayyum M., Abbas F., Hannan F., Rinklebe J., Sik Ok Y. 2017. Effect of biochar on cadmium bioavailability and uptake in wheat (Triticum 
aestivum L.) grown in a soil with aged contamination. Ecotoxicol. Environ. Saf., 140, 37-47. https:// doi.org/10.1016/j.ecoenv.2017.02.028

2. Abideen Z., Koyro H.W., Huchzermeyer B., Ansari R., Zulfiqar F., Gul B. 2020. Ameliorating effects of biochar on photosynthetic efficiency and antioxidant defence of Phragmites karka under drought stress. Plant Biol., 22, 259-266. https://doi.org/10.1111/ plb.13054

3. Aebi H. 1984. Catalase in Vitro. Methods Enzymol., 105, 121-126. https://doi.org/10.1016/ S0076-6879(84)05016-3

4. Ain-Lhout F., Zunzunegui M., Diaz Barradas M.C., Tirado R., Clavijo A., Garcia Novo F. 2001. Comparison of proline accumulation in two mediterranean shrubs subjected to natural and experimental water deficit. Plant Soil, 2302(230), 175-183. https://doi.org/10.1023/A:1010387610098

5. Bates L.S., Waldren R.P., Teare I.D. 1973. Rapid determination of free proline for water-stress studies. Plant Soil, 391(39), 205-207. https://doi. org/10.1007/BF00018060

6. Baxter A., Mittler R., Suzuki N. 2014. ROS as key players in plant stress signalling. J. Exp. Bot. 65, 1229-1240. https://doi.org/10.1093/jxb/ert375

7. Beauchamp C., Fridovich I. 1971. Superoxide dismutase: Improved assays and an assay applicable to acrylamide gels. Anal. Biochem., 44, 276-287. https://doi.org/10.1016/0003-2697(71)90370-8

8. Blakemore L.C., Searle P.L., Daly B.K. 1981. Methods for chemical analysis of soils.

9. Bouqbis L., Daoud S., Claudia H.K., Kammann I. 2016. Biochar from argan shells: production and characterization. Int. J. Recycl. Org. Waste Agric. https://doi.org/10.1007/s40093-016-0146-2

10. Brockhoff S.R., Christians N.E., Killorn R.J., Horton R., Davis D.D. 2010. Physical and MineralNutrition Properties of Sand-Based Turfgrass Root Zones Amended with Biochar. Agron. J., 102, 16271631. https://doi.org/10.2134/agronj2010.0188

11. Carey D.E., McNamara P.J., Zitomer D.H. 2015. Biochar from Pyrolysis of Biosolids for Nutrient Adsorption and Turfgrass Cultivation. Water Environ. Res. A Res. Publ. Water Environ. Fed., 87, 2098-2106. https://doi.org/10.2175/10614301 $5 X 14362865227391$

12. Chance B., Maehly A.C. 1955. Assay of catalases and peroxidases. \{black small square\}. Methods Enzymol., 2, 764-775. https://doi.org/10.1016/ S0076-6879(55)02300-8

13. Cornelissen G., Martinsen V., Shitumbanuma V., Alling V., Breedveld G.D., Rutherford D.W., Sparrevik M., Hale S.E., Obia A., Mulder J. 2013. Biochar Effect on Maize Yield and Soil Characteristics in Five Conservation Farming Sites in Zambia.
Agronomy, 3, 256-274. https://doi.org/10.3390/ agronomy 3020256

14. Corpas F.J., Gupta D.K., Palma J.M. 2015. Production Sites of Reactive Oxygen Species (ROS) in Organelles from Plant Cells. React. Oxyg. Species Oxidative Damage Plants Under Stress, 1-22. https://doi.org/10.1007/978-3-319-20421-5_1

15. Cross A., Sohi S.P. 2011. The priming potential of biochar products in relation to labile carbon contents and soil organic matter status. Soil Biol. Biochem., 43, 2127-2134. https://doi.org/10.1016/j. soilbio.2011.06.016

16. Fetjah D., Ainlhout L., Ihssane B., Houari A., Idardare Z., Bouqbis L. 2021a. Biological, Physico-Chemical and Morphological Analyses of Four Biochars Derived from Agricultural Waste. J. Ecol. Eng., 22, 36-46. https://doi.org/10.12911/22998993/133964

17. Fetjah D., Fatima L., Ainlhout E., Ihssane B., Bouqbis L. 2021b. Effect of Banana Waste Biochar on Physiological Responses and Growth of Seashore Paspalum, 22, 1-10.

18. Fu Q.S., Yang R.C., Wang H.S., Zhao B., Zhou C.L., Ren S.X., Guo Y.-D. 2013. Leaf morphological and ultrastructural performance of eggplant (Solanum melongena L.) in response to water stress. Photosynthetica, 51, 109-114. https://doi.org/10.1007/ s11099-013-0005-6

19. Ghassemi-Golezani K., Farhangi-Abriz S. 2019. Biochar alleviates fluoride toxicity and oxidative stress in safflower (Carthamus tinctorius L.) seedlings. Chemosphere, 223, 406-415. https://doi. org/10.1016/j.chemosphere.2019.02.087

20. Glaser B., Lehmann J., Zech W. 2002. Ameliorating physical and chemical properties of highly weathered soils in the tropics with charcoal - A review. Biol. Fertil. Soils, 35, 219-230. https://doi. org/10.1007/s00374-002-0466-4

21. Hafez Y., Attia K., Alamery S., Ghazy A., Al-Doss A., Ibrahim E., Rashwan E., El-Maghraby L., Awad A., Abdelaal K. 2020. Beneficial effects of biochar and chitosan on antioxidative capacity, osmolytes accumulation, and anatomical characters of waterstressed barley plants. Agronomy, 10, 1-18. https:// doi.org/10.3390/agronomy10050630

22. Hussain M., Malik M.A., Farooq M., Ashraf M.Y., Cheema M.A. 2008. Improving drought tolerance by exogenous application of glycinebetaine and salicylic acid in sunflower. J. Agron. Crop Sci., 194, 193-199. https://doi.org/10.1111/j.1439-037X.2008.00305.x

23. Husson F., Lê S., Mazet J. 2007. FactoMineR: Factor analysisand data mining with $\mathrm{R}$ (Version 1.09.) (software). Availablefromhttp://factominer.free.fr

24. Ibitayo O., Jd B., Mj B. 1981. Cold Hardiness Of Bermudagrass And Paspalum Vaginatum Sw. Cold Hardiness Bermudagrass Paspalum Vaginatum Sw. 
25. Ibrahim M., Li G., Chan F.K.S., Kay P., Liu X.X., Firbank L., Xu Y.Y. 2019. Biochars effects potentially toxic elements and antioxidant enzymes in Lactuca sativa L. grown in multi-metals contaminated soil. Environ. Technol. Innov., 15, 100427. https://doi.org/10.1016/j.eti.2019.100427

26. Jaiswal A.K., Alkan N., Elad Y., Sela N., Philosoph A.M., Graber E.R., Frenkel O. 2020. Molecular insights into biochar-mediated plant growth promotion and systemic resistance in tomato against Fusarium crown and root rot disease. Sci. Rep., 10, 1-15. https://doi.org/10.1038/s41598-020-70882-6

27. Kammann C.I., Linsel S., Gößling J.W., Koyro H.W. 2011. Influence of biochar on drought tolerance of Chenopodium quinoa Willd and on soil-plant relations. Plant Soil, 345, 195-210. https://doi. org/10.1007/s11104-011-0771-5

28. Lehmann J., Pereira da Silva Jr J., Steiner C., Nehls T., Zech W., Glaser B. 2003a. Nutrient availability and leaching in an archaeological Anthrosol and a Ferralsol of the Central Amazon basin: fertilizer, manure and charcoal amendments. Plant Soil, 249, 343-357.

29. Lehmann J., Silva Jr J.P., Steiner C., Nehls T., Zech W., Glaser B. 2003b. Nutrient availability and leaching an an archaeological Anthrosol and a Ferralsol. Plant Soil, 249, 343-357.

30. Lichtenthaler H.K., 1987. Chlorophylls and carotenoids: Pigments of photosynthetic biomembranes, in: Methods in Enzymology, Plant Cell Membranes. Academic Press, 350-382.

31. Liu Y., Lu H., Yang S., Wang Y. 2016. Impacts of biochar addition on rice yield and soil properties in a cold waterlogged paddy for two crop seasons. F. Crop. Res., 191, 161-167. https://doi.org/10.1016/j. fcr.2016.03.003

32. Metson A.J. 1956. Methods of chemical analysis for soil survey samples. Agron. J., 12, 208. https:// doi.org/https://doi.org/10.2134/agronj1957.000219 62004900040024x

33. Nakano Y., Asada K. 1981. Hydrogen peroxide is scavenged by ascorbate-specific peroxidase in spinach chloroplasts. Plant Cell Physiol., 22, 867-880. https://doi.org/10.1093/oxfordjournals.pcp.a076232

34. Nikpour-Rashidabad N., Tavasolee A., Torabian S., Farhangi-Abriz S. 2019. The effect of biochar on the physiological, morphological and anatomical characteristics of mung bean roots after exposure to salt stress. Arch. Biol. Sci., 71, 321-327.

35. Pagès J. 2004. Multiple factor analysis: Main features and application to sensory data. Revista
Colombiana de Estadística, 27(1).

36. Paneque M., De la Rosa J.M., Franco-Navarro J.D., Colmenero-Flores J.M., Knicker H. 2016. Effect of biochar amendment on morphology, productivity and water relations of sunflower plants under nonirrigation conditions. Catena, 147, 280-287. https:// doi.org/10.1016/j.catena.2016.07.037

37. Rehman M., Liu L., Bashir S., Saleem M.H., Chen C., Peng D., Siddique K.H. 2019. Influence of rice straw biochar on growth, antioxidant capacity and copper uptake in ramie (Boehmeria nivea L.) grown as forage in aged copper-contaminated soil. Plant Physiol. Biochem., 138, 121-129. https://doi. org/10.1016/j.plaphy.2019.02.021

38. Sairam R.K., Rao K., Srivastava G.C. 2002. Differential response of wheat genotypes to long term salinity stress in relation to oxidative stress, antioxidant activity and osmolyte concentration. Plant Sci., 163, 1037-1046. https://doi.org/10.1016/ S0168-9452(02)00278-9

39. Tanure M.M.C., da Costa L.M., Huiz H.A., Fernandes R.B.A., Cecon P.R., Pereira Junior J.D., da Luz J.M.R. 2019. Soil water retention, physiological characteristics, and growth of maize plants in response to biochar application to soil. Soil Tillage Res. 192, 164-173. https://doi.org/10.1016/j. still.2019.05.007

40. Vaughn S.F., Dinelli F.D., Jackson M.A., Vaughan M.M., Peterson S.C. 2018. Biochar-organic amendment mixtures added to simulated golf greens under reduced chemical fertilization increase creeping bentgrass growth. Ind. Crops Prod., 111, 667-672. https://doi.org/https://doi.org/10.1016/j. indcrop.2017.11.036

41. Wang Y., Pan F., Wang G., Zhang G., Wang Y., Chen X., Mao Z. 2014. Effects of biochar on photosynthesis and antioxidative system of Malus hupehensis Rehd. seedlings under replant conditions. Sci. Hortic. (Amsterdam)., 175, 9-15. https://doi. org/10.1016/j.scienta.2014.05.029

42. Xu Z., Zhou G. 2008. Responses of leaf stomatal density to water status and its relationship with photosynthesis in a grass, 59, 3317-3325. https://doi. org/10.1093/jxb/ern 185

43. Zunzunegui M., Ruiz-Valdepeñas E., Sert M.A., Díaz-Barradas M.C., Gallego-Fernández J.B. 2020. Field comparison of ecophysiological traits between an invader and a native species in a Mediterranean coastal dune. Plant Physiol. Biochem., 146, 278286. https://doi.org/10.1016/j.plaphy.2019.11.032 